\title{
Cutaneous Horn
}

\author{
Siddharth P. Dubhashi*, Vivek D. Kulkarni, Adil Suleman, Ishant Rege, Harsh Kumar \\ Dr. D.Y.Patil Medical College, Hospital and Research Centre, Dr. D.Y. Patil Vidyapeeth, Pune, India \\ Email: spdubhashi@gmail.com
}

Received 5 August 2014; revised 19 September 2014; accepted 22 October 2014

Copyright (C) 2014 by authors and OALib.

This work is licensed under the Creative Commons Attribution International License (CC BY). http://creativecommons.org/licenses/by/4.0/

\section{(c) (i) Open Access}

\begin{abstract}
A cutaneous horn (corn cutaneum) is a dense, hyperkeratotic conical projection of skin arising from an unusual cohesiveness of keratinized material. Cutaneous horns most frequently occur in sites that are exposed to actinic radiation or burns. Forearm, cartilaginous portion of the ear, legs, and hands may also be affected. Cutaneous horns can occur in sun protected areas. Histologic confirmation is necessary to rule out malignant changes. No clinical features reliably distinguish between benign and malignant lesions. This is a case report of a cutaneous horn over inguinal region.
\end{abstract}

\section{Keywords}

\author{
Cutaneous Horn, Keratinized Material, Histology \\ Subject Areas: Dermatology, Surgery \& Surgical Specialties
}

\section{Introduction}

A cutaneous horn (corn cutaneum) is a dense, hyperkeratotic conical projection of skin arising from an unusual cohesiveness of keratinized material [1]. Cutaneous horns most frequently occur in sites that are exposed to actinic radiation or burns. Forearm, cartilaginous portion of the ear, legs, and hands may also be affected [2]. They are thought to result from underlying benign, premalignant or malignant pathology, in $61.1 \%, 23.2 \%$ and $15.7 \%$ of cases respectively [3]. Histologic confirmation is necessary to rule out malignant changes. No clinical features reliably distinguish between benign and malignant lesions.

\section{Case Report}

A 16-year-old female patient presented with a slowly growing horny projection $6 \times 3 \mathrm{~cm}$ size over the left inguinal region since 9 years (Figure 1 ).

There was no history of pain or discharge associated with the lesion. There was no regional lymphadenopathy. A clinical diagnosis of cutaneous horn was made. The lesion was excised under spinal anaesthesia with an ellip-

\footnotetext{
${ }^{*}$ Corresponding author.
} 
tical incision with primary closure of defect. The histopathological examination revealed hyperplastic skin. The epidermis showed hyperkeratosis, follicular plugging, irregular acanthosis, elongated rete ridges. The papillary dermis showed proliferation of numerous dilated thin walled congested capillaries. The stroma showed mild chronic inflammation and pigment laiden macrophages. Features were suggestive of angiokeratoma (Figure 2).

\section{Discussion}

Cutaneous horns are cornified skin growths shaped in the form of a horn. They differ from true animal horns in not having a bony core [2] [4]. The earliest documented case of cutaneous horn is from London in 1558 [5]. The earliest observations on cutaneous horn in humans were described by the London Surgeon Everard Home in 1791 [6]. Farris from Italy first described the large horn in man with adequate histological findings [7]. Cutaneous horns can occur even in the sun protected areas. The hyperkeratosis that results in horn formation develops over the surface of a hyperproliferative lesion. The underlying condition can be benign (seborrheic keratitis, angiokeratoma, histiocytoma, follicular keratosis, molluscumcontagiosum, epidermal naevus, etc.) pre-malignant (solar keratosis, Bowens disease, arsenical keratosis) or malignant (squamous cell carcinoma, sebaceous carcinoma, Kaposi's sarcoma) [8]. Yu et al. in their study of 643 cases, have reported malignant lesions in 39\% patients [3]. Certain risk factors for malignancy have been put forth, viz large size, a wide base relative to height, tenderness at the base, advanced age and the male sex [3]. Complete excision is the treatment of choice and histopathological examination of the base of the lesion is extremely crucial [8]. Other treatment modalities such as electrodessication, laser ablation and cryosurgery have also been described [5]. However, valuable information regarding basic pathology may be lost with use of these methods.

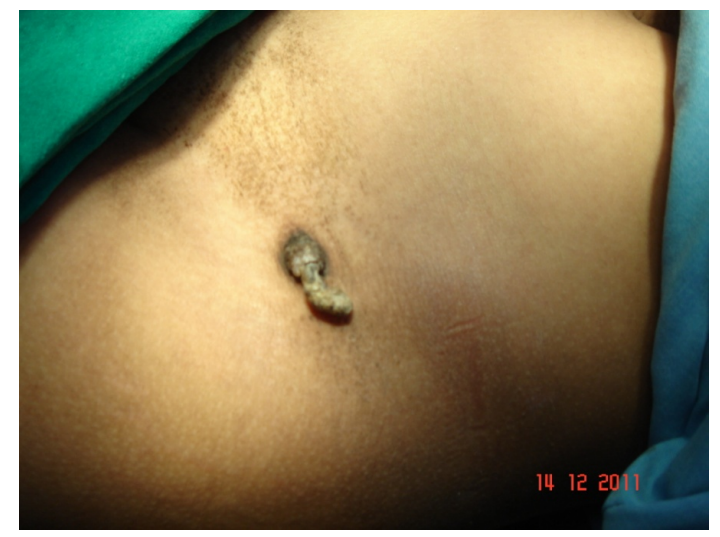

Figure 1. Sebaceous horn in left inguinal region.

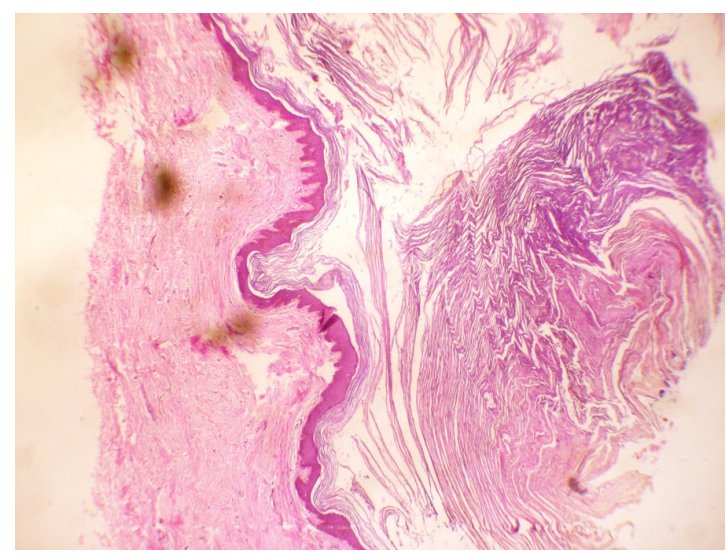

Figure 2. Epidermis shows irregular acanthosis with hyperkeratosis and follicular plugging. The rete ridges are elongated. The dermis shows numerous thin walled congested blood vessels. H\&E $\times 100$. 


\section{Conclusion}

Cutaneous horns can occur in sun protected areas. Though cutaneous horns predominantly present as benign lesions, it should not be neglected. The possibility of a skin malignancy should always be kept in mind.

\section{References}

[1] Nthumba, P.M. (2007) Giant Cutaneous Horn in an African Woman: A Case Report. Journal of Medical Case Reports, 1, 170. http://dx.doi.org/10.1186/1752-1947-1-170

[2] Souza, L.N., Martins, C.R. and de Paula, A.M. (2003) Cutaneous Horn Occurring on the Lip of a Child. International Journal of Paediatric Dentistry, 13, 365-367. http://dx.doi.org/10.1046/j.1365-263X.2003.00481.x

[3] Yu, R.C.H., Pryce, D.W., Macfarlane, A.W. and Stewart, T.W. (1991) A Histological Study of 643 Cutaneous Horns. British Journal of Dermatology, 124, 449-452. http://dx.doi.org/10.1111/j.1365-2133.1991.tb00624.x

[4] Mantese, S.A.O., Diago, P.M., Rocha, A., Berbert, A.L., Ferreira, A.K. and Ferreira, T.C. (2010) Cutaneous Horn: A Retrospective Histopathological Study of 222 Cases. Anais Brasileiros de Dermatologia, 85, 157-163. http://dx.doi.org/10.1590/S0365-05962010000200005

[5] Oludiran, O.O. and Ekanem, V.J. (2011) Cutaneous Horns in an African Population. Journal of Cutaneous and Aesthetic Surgery, 4, 197-200. http://dx.doi.org/10.4103/0974-2077.91253

[6] Bondeson, J. (2001) Everard Home, John Hunter, and Cutaneous Horns: A Historical Review. American Journal of Dermatopathology, 23, 362-369. http://dx.doi.org/10.1097/00000372-200108000-00014

[7] Farris, G. (1953) Histological Considerations on a Case of a Voluminous Cutaneous Horn. Minerva Dermatol, 28, 159-165.

[8] Copcu, E., Sivdioglu, N. and Culhaci, N. (2004) Cutaneous Horns: Are These Lesions as Innocent as They Seem to Be? World Journal of Surgical Oncology, 2, 18. http://dx.doi.org/10.1186/1477-7819-2-18 